(1)

CrossMark

\title{
Crucial role for lung iron level and regulation in the pathogenesis and severity of asthma
}

Md. Khadem Ali ${ }^{1,2}$, Richard Y. Kim²,3, Alexandra C. Brown², Jemma R. Mayall ${ }^{2}$, Rafia Karim², James W. Pinkerton ${ }^{2,4}$, Gang Liu (10 ${ }^{2,3}$, Kristy L. Martin ${ }^{5}$, Malcolm R. Starkey ${ }^{2,6}$, Amber L. Pillar ${ }^{2}$, Chantal Donovan ${ }^{2,3}$, Prabuddha S. Pathinayake ${ }^{7}$, Olivia R. Carroll ${ }^{2}$, Debbie Trinder ${ }^{8}$, Hock L. Tay ${ }^{2}$, Yusef E. Badi ${ }^{9}$, Nazanin Z. Kermani (10 ${ }^{10}$, Yi-Ke Guo $^{10}$, Ritambhara Aryal ${ }^{5}$, Sharon Mumby ${ }^{9}$, Stelios Pavlidis ${ }^{9}$, Ian M. Adcock ${ }^{9}$, Jessica Weaver (D) $^{2}$, Dikaia Xenaki ${ }^{11}$, Brian G. Oliver ${ }^{11}$, Elizabeth G. Holliday ${ }^{12,13}$, Paul S. Foster ${ }^{2}$, Peter A. Wark (1) ${ }^{2,14}$, Daniel M. Johnstone ${ }^{15}$, Elizabeth A. Milward ${ }^{5}$, Philip M. Hansbro ${ }^{2,3,16}$ and Jay C. Horvat ${ }^{2,16}$

@ERSpublications

The relationship between iron and the pathogenesis of asthma remains unclear. Here it is shown for the first time that altered iron responses are a key feature of clinical and experimental asthma and may play important roles in disease. http://bit.ly/36JKajt

Cite this article as: Ali MK, Kim RY, Brown AC, et al. Crucial role for lung iron level and regulation in the pathogenesis and severity of asthma. Eur Respir J 2020; 55: 1901340 [https://doi.org/10.1183/ 13993003.01340-2019].

ABSTRACT Accumulating evidence highlights links between iron regulation and respiratory disease. Here, we assessed the relationship between iron levels and regulatory responses in clinical and experimental asthma.

We show that cell-free iron levels are reduced in the bronchoalveolar lavage (BAL) supernatant of severe or mild-moderate asthma patients and correlate with lower forced expiratory volume in $1 \mathrm{~s}\left(\mathrm{FEV}_{1}\right)$. Conversely, iron-loaded cell numbers were increased in BAL in these patients and with lower $\mathrm{FEV}_{1} /$ forced vital capacity (FVC) ratio. The airway tissue expression of the iron sequestration molecules divalent metal transporter 1 (DMT1) and transferrin receptor 1 (TFR1) are increased in asthma, with TFR1 expression correlating with reduced lung function and increased Type-2 (T2) inflammatory responses in the airways. Furthermore, pulmonary iron levels are increased in a house dust mite (HDM)-induced model of experimental asthma in association with augmented Tfr1 expression in airway tissue, similar to human disease. We show that macrophages are the predominant source of increased Tfr1 and $\mathrm{Tfr}^{+}$macrophages have increased $I l 13$ expression. We also show that increased iron levels induce increased pro-inflammatory cytokine and/or extracellular matrix (ECM) responses in human airway smooth muscle (ASM) cells and fibroblasts ex vivo and induce key features of asthma in vivo, including airway hyper-responsiveness (AHR) and fibrosis, and T2 inflammatory responses.

Together these complementary clinical and experimental data highlight the importance of altered pulmonary iron levels and regulation in asthma, and the need for a greater focus on the role and potential therapeutic targeting of iron in the pathogenesis and severity of disease.

This article has been corrected according to the erratum published in the September 2022 issue of the European Respiratory Journal.

This article has supplementary material available from erj.ersjournals.com

Received: 06 July 2019 | Accepted after revision: 28 Jan 2020

Copyright @ERS 2020 


\section{Introduction}

Clinical and experimental evidence suggests that altered levels of systemic and lung iron and/or iron regulatory molecules are associated with lung inflammation in many diseases, including asthma [1]. Chronic inflammatory responses that underpin many respiratory diseases are associated with decreased systemic iron levels $[2,3]$. There is a correlation between low maternal iron status during pregnancy and childhood wheezing, impaired lung function and atopic sensitisation [4]. In addition, low foetal iron is linked with increased susceptibility to eosinophilia in infancy [5]. In a longitudinal study of parents and children, higher umbilical cord iron status was associated with decreased occurrence of wheezing and eczema, while lower iron status was linked to increased risk of atopy [6]. Furthermore, lower serum and exhaled breath condensate iron levels are associated with asthma in children and adults [7-9]. However, plasma iron and malondialdehyde levels, a marker of oxidative stress, are significantly elevated in asthmatic subjects compared to healthy controls $[10,11]$. Ferritin levels are increased in the lungs in an experimental mouse model of asthma [12]. Ferritin and iron levels were reduced by intranasal administration of iron chelator complexes in this model, with treatment also attenuating inflammation [12]. By contrast, short-term intraperitoneal injection of iron dextran suppresses hallmark features of asthma in an acute mouse model [13], suggesting that increasing systemic iron levels may protect against disease. However, the potential pathological effects of chronically increasing systemic iron levels and the effects on iron accumulation in the lung on asthma, remain unexplored. Together, these findings provide evidence that asthma is associated with altered iron homeostasis. However, it is unclear whether altered iron levels play roles in pathogenesis or are a consequence of disease. Further clinical and experimental studies investigating the link between iron and asthma are required to better understand the mechanisms involved and address whether increased or decreased pulmonary iron levels are detrimental. In order to address this, we assessed the levels of iron and iron-related gene expression in the airways of patients with severe or mild-moderate asthma and in healthy controls. We show that altered iron metabolism in the airways is associated with asthma. Specifically, reduced extracellular iron levels and increased cellular iron accumulation and airway transferrin receptor 1 (TFR1) expression are linked with disease severity, suggesting that iron sequestration/accumulation in cells/tissues may play a role in asthma pathogenesis. We also show that experimental asthma is associated with increased airway Tfr1 expression that corresponds with increased pulmonary iron accumulation. These findings have led us to hypothesise that increased iron accumulation in the lung plays a key role in driving the key features of asthma. We confirmed this by showing that increased lung iron levels in two murine models of iron overload result in the development of key asthma features similar to that observed in house dust mite (HDM)-induced experimental disease.

\section{Methods}

Full details are provided in the supplementary material.

\section{Study approvals}

All experiments were conducted with approval of the Human/Animal Ethics Committees of the University of Newcastle (Australia) and the local ethics committees of the Unbiased BIOmarkers in PREDiction of respiratory disease outcomes (U-BIOPRED) clinical centres.

Affiliations: 'Division of Pulmonary and Critical Care Medicine, Stanford University, Stanford, CA, USA. ${ }^{2}$ Priority Research Centre for Healthy Lungs, Hunter Medical Research Institute and School of Biomedical Sciences and Pharmacy, University of Newcastle, Newcastle, Australia. ${ }^{3}$ Centre for Inflammation, Centenary Institute and University of Technology Sydney, Sydney, Australia. ${ }^{4}$ Respiratory Pharmacology and Toxicology Group, National Heart and Lung Institute, Imperial College London, London, UK. ${ }^{5}$ School of Biomedical Sciences and Pharmacy, University of Newcastle, Newcastle, Australia. ${ }^{6}$ Dept of Immunology and Pathology, Central Clinical School, Monash University, Melbourne, Australia. ${ }^{7}$ Priority Research Centre for Healthy Lungs, Hunter Medical Research Institute and School of Medicine and Public Health, University of Newcastle, Newcastle, Australia. ${ }^{8}$ Medical School, Harry Perkins Medical Research Institute, University of Western Australia, Fiona Stanley Hospital, Perth, Australia. ${ }^{9}$ Airway Disease Section, National Heart and Lung Institute, Imperial College London, London, UK. ${ }^{10}$ Data Science Institute, Dept of Computing, Imperial College London, London, UK. ${ }^{11}$ Woolcock Institute of Medical Research, University of Sydney and School of Life Sciences, University of Technology Sydney, Sydney, Australia. ${ }^{12}$ Hunter Medical Research Institute, New Lambton, Australia. ${ }^{13}$ School of Medicine and Public Health, University of Newcastle, Callaghan, Australia. ${ }^{14}$ Dept of Respiratory and Sleep Medicine, John Hunter Hospital, Newcastle, Australia. ${ }^{15}$ Discipline of Physiology and Bosch Institute, University of Sydney, Sydney, Australia. ${ }^{16}$ These authors contributed equally.

Correspondence: Jay C. Horvat, School of Biomedical Sciences and Pharmacy, Faculty of Health and Medicine, The University of Newcastle, University Drive, Callaghan, New South Wales, 2308, Australia. E-mail: jay.horvatanewcastle.edu.au 


\section{Clinical analyses}

Levels of iron were assessed in bronchoalveolar lavage (BAL) cells from 11 severe asthma patients, 12 mild-moderate asthma patients and 13 healthy controls using Perls' staining with 3,3'-diaminobenzidine tetrahydrochloride (DAB). In the same cohorts, iron regulatory factors were assessed in airway biopsy tissues using quantitative PCR. Colorimetric non-haem iron (NHI) assay was used to measure NHI content in BAL supernatants collected from a second set of severe asthma patients, mild-moderate asthma patients and healthy controls (ten subjects per group). In both sets of donors, asthma severity was categorised based on \% predicted forced expiratory volume in $1 \mathrm{~s}\left(\mathrm{FEV}_{1}\right)$ and asthma severity symptoms $\cdot$ day $^{-1} \cdot$ night $^{-1}$ (tables 1 and 2). The transcriptomic profile of iron regulatory factors was analysed in bronchial brushings of 39 severe asthma patients, 29 mild-moderate asthma patients and 40 healthy controls within the U-BIOPRED cohort [14].

Iron overloaded mice; experimental asthma model; iron quantification; airway inflammation; small airway fibrosis; lung function, flow cytometry analyses of different cell populations in murine lung tissue, human primary ASM and lung fibroblast cell culture, primary bronchial airway epithelial cells (pBECs) cultured at the air-liquid interface (ALI)

Haemochromatosis protein gene (Hfe)-deficient $\left(\mathrm{Hfe}^{-/-}\right)$and wild-type (WT) mice on an AKR background (at 36 weeks old) [15] and WT BALB/c mice (at 8 weeks old) were fed a high iron diet (HID), supplemented with $2 \%$ carbonyl iron, for 8 weeks and used to model iron overload. HDM-induced experimental asthma was induced in $\mathrm{Hfe}^{-/-}$mice and WT BALB/c mice fed a HID, a normal diet (called control chow (CC)) or a low iron diet (LID) (see supplemental figure E1). Iron quantification, airway inflammation, small airway fibrosis, lung function, pulmonary cell population characterisation, and cytokine and extracellular matrix (ECM) responses in human primary airway smooth muscle (ASM) cells and lung fibroblasts, as well as iron-related gene expression in primary bronchial airway epithelial cells (pBECs), were assessed as previously described [16-34] and as outlined in the supplementary material.

\section{Statistics}

Comparisons between two groups were performed using a non-parametric Mann-Whitney test. Comparisons between multiple groups were performed using Kruskal-Wallis one-way ANOVA with an uncorrected Dunn's post-hoc test. Airway hyper-responsiveness (AHR) data were analysed using two-way repeated measures ANOVA with a Bonferroni post-hoc test. Correlation analyses were performed using Spearman's rank correlation.

TABLE 1 Human sample donor characteristics (iron metabolism genes expression in airway biopsy tissues and iron scores in bronchoalveolar lavage (BAL) cells)

\begin{tabular}{|c|c|c|c|}
\hline Characteristic & Healthy & Mild-moderate asthmatics & Severe asthmatics \\
\hline Subjects & 13 & 12 & 11 \\
\hline Age years & $53.00 \pm 4.729$ & $55.92 \pm 4.583$ & $53.73 \pm 3.681$ \\
\hline Male/female & $4 / 9$ & $6 / 6$ & $2 / 9$ \\
\hline BMI $\mathrm{kg} \cdot \mathrm{m}^{-2}$ & & $31.22 \pm 2.302$ & $31.71 \pm 4.313$ \\
\hline FEV $_{1} \%$ predicted & $102.7 \pm 4.494$ & $86.92 \pm 2.726^{* *}$ & $76 \pm 5.389 * * *$ \\
\hline $\mathrm{FEV}_{1} / \mathrm{FVC}$ & $0.817 \pm 0.021$ & $0.730 \pm 0.016^{* *}$ & $0.656 \pm 0.049 * *$ \\
\hline $\mathrm{ACQ}$ & & $0.903 \pm 0.168$ & $2.166 \pm 0.291^{\# \#}$ \\
\hline Total cells $\times 10^{6} \cdot \mathrm{mL}^{-1}$ BAL & $0.170 \pm 0.026$ & $0.129 \pm 0.021$ & $0.853 \pm 0.327 *, \#$ \\
\hline Macrophages $\times 10^{6} \cdot \mathrm{mL}^{-1} \mathrm{BAL}$ & $0.053 \pm 0.011$ & $0.068 \pm 0.021$ & $0.128 \pm 0.031 *$ \\
\hline Neutrophils $\times 10^{6} \cdot \mathrm{mL}^{-1}$ BAL & $0.065 \pm 0.013$ & $0.031 \pm 0.010$ & $0.653 \pm 0.311$ \\
\hline Eosinophils $\times 10^{6} \cdot \mathrm{mL}^{-1}$ BAL & $0.002 \pm 0.000$ & $0.039 \pm 0.017$ & $0.050 \pm 0.019 *$ \\
\hline ICS yes/no & NA & $9 / 3$ & $11 / 0$ \\
\hline ICS dose ${ }^{\#}$ & NA & $543.30 \pm 126.70$ & $800.00 \pm 80.90$ \\
\hline LABA yes/no & NA & $6 / 6$ & $11 / 0$ \\
\hline LAMA yes/no & NA & $4 / 8$ & $5 / 6$ \\
\hline SABA yes/no & NA & $5 / 7$ & $5 / 6$ \\
\hline OCS yes/no & NA & $0 / 12$ & $2 / 9$ \\
\hline
\end{tabular}

Data are presented as $\mathrm{n}$ or mean \pm SEM. BMI: body mass index; $\mathrm{FEV}_{1}$ : forced expiratory volume in $1 \mathrm{~s} ; \mathrm{FVC}$ : forced vital capacity; ACQ: asthma control questionnaire; NA: not applicable; ICS: inhaled corticosteroids; LABA: long-acting $\beta_{2}$-agonist; LAMA: long-acting muscarinic antagonist; SABA: short-acting $\beta$-agonist; OCS: oral corticosteroids. ${ }^{\#}$ : equivalent to fluticasone $\left(\mu \mathrm{g} \cdot \mathrm{day}^{-1}\right) .{ }^{*}: \mathrm{p}<0.05$ compared to healthy controls; ${ }^{* *}$ : $p<0.01$ compared to healthy controls; ${ }^{* * *}: p<0.001$ compared to healthy controls; ${ }^{\#}: p<0.05$ compared to mild-moderate asthmatics; ${ }^{\# \#}: p<0.01$ compared to mild-moderate asthmatics. 


\section{Results}

In asthma, iron levels in BAL supernatant are reduced, but iron-positive cell numbers are increased

We first assessed cell-free NHI levels and iron-loaded cell numbers in BAL obtained from severe or mildmoderate asthma patients and healthy controls. Iron levels in BAL supernatant were reduced in combined severe and mild-moderate asthma patients compared to healthy controls, with the greatest decrease in severe disease (figures $1 \mathrm{a}$ and $1 \mathrm{~b}$ ). NHI levels positively correlate with \% predicted $\mathrm{FEV}_{1}$ but not with $\mathrm{FEV}_{1} /$ forced vital capacity (FVC) (figures $1 \mathrm{c}$ and $1 \mathrm{~d}$ ). NHI levels negatively correlate with inhaled corticosteroids (ICS) used in asthma patients (figure 1e). In contrast, severe and mild-moderate asthma patients have increased numbers of iron-positive cells in BAL compared to healthy controls (figures 1f-1h). Iron-positive $\mathrm{BAL}$ cell numbers negatively correlate with $\mathrm{FEV}_{1} / \mathrm{FVC}$ but not with \% predicted $\mathrm{FEV}_{1}$ (figures $1 \mathrm{i}$ and $1 \mathrm{j}$ ). Together, these novel findings show that decreased extracellular iron levels in the airway lumen, but increased iron in BAL cells, correlates with declines in lung function in asthma, suggesting a relationship between cellular sequestration/accumulation of iron and impaired lung function.

\section{Levels of key iron sequestration molecules are increased in the airways of asthma patients}

We next assessed whether levels of iron sequestration molecules (divalent metal transporter 1 (DMT1) and TFR1) are increased in the airways of asthma patients. DMT1and TFR1 mRNA expression are increased in the airways of asthma patients compared to healthy controls (figures $2 \mathrm{a}$ and $2 \mathrm{~d}$ ). In addition, DMT1 and TFR1 expression negatively correlates with $\mathrm{FEV}_{1} / \mathrm{FVC}$ with similar correlations observed for \% predicted $\mathrm{FEV}_{1}$ (figures $2 \mathrm{~b}, 2 \mathrm{c}, 2 \mathrm{e}$ and $2 \mathrm{f}$ ). We confirmed that TFR1 expression is increased using airway brushings from a separate cohort of asthma patients (figure 2g). Importantly, TFR1 expression is strongly and positively associated with Group 2 innate lymphoid cell (ILC2) [35], interleukin 4 (IL4), IL5 and IL13 expression (figures $2 \mathrm{~h}-2 \mathrm{k}$ ). Collectively, these data provide evidence that increased iron sequestration into airway tissues and/or cells due to increased DMT1 and TFR1 expression may play a crucial role in the pathogenesis and severity of asthma.

\section{Expression of iron uptake, transport, storage and regulatory factors are altered in the airways} and pBECs of asthma patients

We next assessed whether the expression of other iron-related genes is altered in the airways of asthma patients. Severe asthma patients have increased expression of iron uptake molecules (transferrin receptor 2 (TFR2), zinc transporter (ZIP14) and natural resistance-associated macrophage protein 1 (NRAMP1) $(\mathrm{p}=0.08))$ and iron storage molecules (ferritin heavy chain $(F T H)(\mathrm{p}=0.06))$ compared to healthy controls

TABLE 2 Human sample donor characteristics (non-haem iron (NHI) quantification in bronchoalveolar lavage (BAL))

\begin{tabular}{|c|c|c|c|}
\hline Characteristic & Healthy & Mild-moderate asthmatics & Severe asthmatics \\
\hline Subjects & 10 & 10 & 10 \\
\hline Age years & $58.56 \pm 2.724$ & $60.70 \pm 5.327$ & $56.00 \pm 3.841$ \\
\hline Male/female & $4 / 6$ & $5 / 5$ & $5 / 5$ \\
\hline $\mathrm{FEV}_{1} \%$ predicted & $97.5 \pm 5.861$ & $89.6 \pm 4.759$ & $66.33 \pm 7.427^{* *}, \#$ \\
\hline $\mathrm{FEV}_{1} / \mathrm{FVC}$ & $0.812 \pm 0.008$ & $0.741 \pm 0.023 *$ & $0.745 \pm 0.035$ \\
\hline$A C Q$ & & $4.778 \pm 0.8127$ & $7.333 \pm 3.18$ \\
\hline Total cells $\times 10^{6} \cdot \mathrm{mL}^{-1} \mathrm{BAL}$ & $0.110 \pm 0.028$ & $0.138 \pm 0.027$ & $0.126 \pm 0.016$ \\
\hline Macrophages $\times 10^{6} \cdot \mathrm{mL}^{-1} \mathrm{BAL}$ & $0.037 \pm 0.009$ & $0.031 \pm 0.008$ & $0.051 \pm 0.013$ \\
\hline Neutrophils $\times 10^{6} \cdot \mathrm{mL}^{-1}$ BAL & $0.025 \pm 0.009$ & $0.053 \pm 0.022$ & $0.039 \pm 0.008$ \\
\hline Eosinophils $\times 10^{6} \cdot \mathrm{mL}^{-1} \mathrm{BAL}$ & $0.000 \pm 0.000$ & $0.020 \pm 0.011$ & $0.029 \pm 0.012$ \\
\hline ICS yes/no & NA & $8 / 2$ & $10 / 0$ \\
\hline ICS dose & NA & $432.0 \pm 110.4$ & $1063 \pm 174.2$ \\
\hline LABA yes/no & NA & $5 / 5$ & $10 / 0$ \\
\hline LAMA yes/no & NA & $2 / 8$ & $6 / 4$ \\
\hline SABA yes/no & NA & $4 / 6$ & $4 / 6$ \\
\hline OCS yes/no & NA & $0 / 10$ & $0 / 10$ \\
\hline
\end{tabular}

Data are presented as $\mathrm{n}$ or mean \pm SEM. BMI: body mass index; $\mathrm{FEV}_{1}$ : forced expiratory volume in $1 \mathrm{~s}$; FVC: forced vital capacity; ACQ: asthma control questionnaire; NA: not applicable; ICS: inhaled corticosteroids; LABA: long-acting $\beta_{2}$-agonist; LAMA: long-acting muscarinic antagonist; SABA: short-acting $\beta$-agonist; OCS: oral corticosteroids. ${ }^{\#}$ : equivalent to fluticasone $\left(\mu \mathrm{g} \cdot \mathrm{day}^{-1}\right) .^{*}$ : $p<0.05$ compared to healthy controls; ${ }^{* *}$ : $p<0.01$ compared to healthy controls; ${ }^{\#}$ : $p<0.05$ compared to mildmoderate asthmatics. 
(figures 3a-3d). The levels of NRAMP1, FTH, ferritin light chain (FTL) and iron regulatory protein 1 (IRP1) expression are significantly higher in the airways of mild asthma patients compared to healthy controls (figures 3c-3f). Hepcidin (HAMP) expression is decreased in the airways of severe asthma patients compared to healthy controls $(\mathrm{p}=0.06)$ (figure $3 \mathrm{~g}$ ). Interestingly, FTL is lower in severe asthma patients compared to mild asthma patients (figure $3 \mathrm{e}$ ). Notably, there is no significant change in iron exporter ferroportin (FPN) expression in any of the groups (figure $3 \mathrm{~h}$ ). Together these data show that factors associated with increased intracellular iron uptake and storage are largely increased in the airways of asthma patients, which may explain the decreases in extracellular iron levels in BAL supernatant and increased iron accumulation in cells/tissues.

To explore which cells are associated with altered iron in the airways, we next assessed expression of DMT1, TFR1, TFR2, ZIP14, NRAMP1, FTH, FTL, IRP1, and FPN in pBECs obtained from asthmatic patients and healthy controls cultured at the air-liquid interface (ALI). As with the mRNA expression changes observed in airway tissue biopsy and bronchial brushings, we observed that TFR1 and TFR2 expression are significantly increased in the pBECs of asthmatic patients (figures $3 \mathrm{j}$ and $3 \mathrm{k}$ ). There is no significant change in expression of any other factors (figures $3 i$ and $31-3 q$ ).

\section{Iron levels and $\mathrm{Tfr}^{+}$macrophages are increased in HDM-induced experimental asthma and increased iron induces pathological responses in ASM cells and lung fibroblasts}

We next determined whether the levels of iron and regulatory factors are similarly altered in HDM-induced experimental asthma (see supplemental figure E2) and whether exogenous iron alters cytokines and ECM responses in primary human ASM cells and lung fibroblasts. We also show that HDM-induced experimental asthma is associated with the accumulation of NHI in lung tissue (figure 4a) and with iron accumulation mostly in macrophages around the airways (figure $4 \mathrm{~b}$ ). We found increased numbers of iron-positive cells in BAL (figure 4c) and increased expression of Tfr1 in the airways (figure 4d), as well as increased transferrin levels in BAL supernatant (figure 4e). Together, our clinical and experimental data provide evidence for increased iron accumulation in lung tissues and cells in asthma that are either playing a role in, and/or are a consequence of, the pathogenesis of asthma. We next assessed the cellular source of increased Tfr1 using flow cytometry. We show that the number of Tfr $1^{+}$ cells is increased in HDM-challenged mice and that these cells are predominantly alveolar and interstitial macrophages (figure 4f). These data suggest that HDM-induced experimental asthma is characterised by an increase in macrophages that sequester iron. To determine whether these $\mathrm{Tfr}^{+}$macrophage populations have a different phenotype, we measured expression of Il10, transforming growth factor beta (Tgfb), interferon gamma (Ifng) and $I l 13$ in $\mathrm{Tfr}^{+}$and $\mathrm{Tfr}^{-}$macrophages in HDM-induced experimental asthma and saline-challenged controls (figures $4 \mathrm{~g}-4 \mathrm{j}$ ). We show that $\mathrm{Tfr}^{+}$macrophages from HDMchallenged mice have increased Il10 and Il13 expression compared to those from saline-challenged controls, as well $\mathrm{Tfr}^{-}$macrophages from both saline-challenged and HDM-challenged groups (figures $4 \mathrm{~g}$ and $4 \mathrm{j}$ ). This suggests that iron-sequestering $\mathrm{Tfr}^{+}$macrophages may play a pathologic role in asthma by promoting Type- 2 (T2) inflammatory responses. To further characterise the potential effects of increased extracellular iron levels in tissues, we also exposed human ASM cells and fibroblasts to increasing concentrations of ferric ammonium citrate (FAC). Increasing concentrations of FAC increase pro-inflammatory cytokine production (IL6 and IL8) and/or ECM gene expression (tenascin C (TNC)) by these cells (figures $4 \mathrm{k}-4 \mathrm{p}$ ).

\section{$\mathrm{Hfe}^{-l-}$ iron overload mice have increased iron levels in the lung associated with increased features of asthma}

We next assessed the consequences of increased iron accumulation in lung tissues and cells on the pathogenesis and severity of key features of asthma using murine models of iron overload. In the absence of HDM treatment, sham phosphate-buffered saline (PBS)-treated $\mathrm{Hfe}^{-/-}$mice, which overload iron systemically (e.g. in the liver) (figure 5a), have significantly higher lung iron levels compared to sham-treated WT controls (figure 5b). Whilst HDM increases iron levels in the lungs of WT mice compared to sham-treated WT controls, it does not further enhance levels in $\mathrm{Hfe}^{-/-}$mice (figure 5b). Increased iron in all groups is predominantly deposited in macrophages surrounding the airways and in the alveoli (figure 5c).

We also demonstrate that the increased iron accumulation observed in sham-treated $\mathrm{Hfe}^{-/-}$mice is associated with increases in leukocyte numbers in BAL and lung interleukin 13 (Il13) expression, which lead to small airway fibrosis and AHR compared to sham-treated WT controls (figures $5 \mathrm{~d}, 5 \mathrm{e}$ and $5 \mathrm{j}-5 \mathrm{~m}$ ). Indeed, these features are similar to those observed in HDM-treated WT controls. HDM treatment in $\mathrm{Hfe}^{-/-}$mice increases the severity of all of the disease features compared to HDM-treated WT controls (figures $5 \mathrm{~d}, 5 \mathrm{e}$ and $5 \mathrm{j}-5 \mathrm{~m}$ ). Together, these data demonstrate that pulmonary iron accumulation alone can drive key features of asthma and that a combination of iron overload and HDM treatment may contribute to more severe features of experimental asthma. 

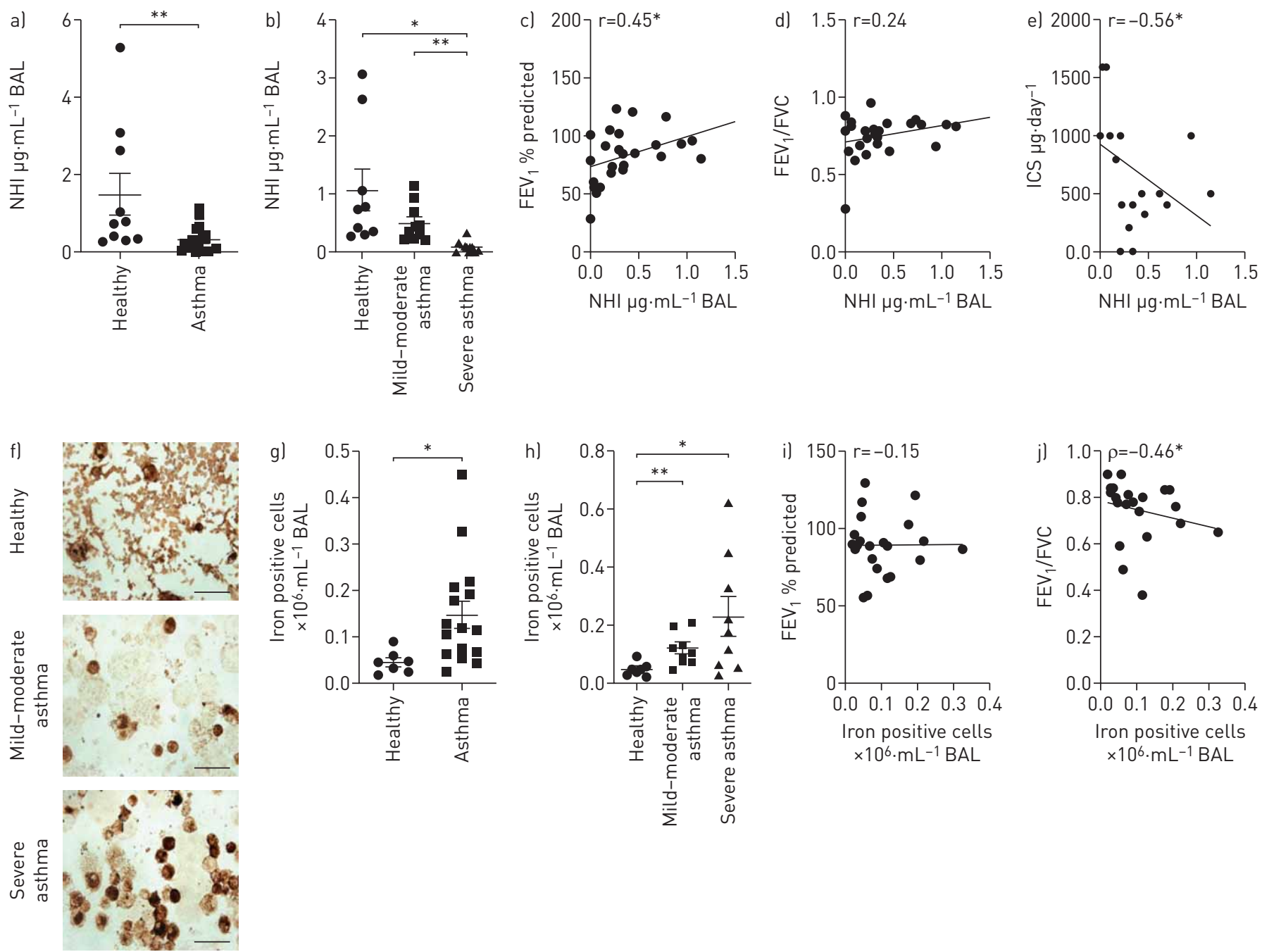

FIGURE 1 Iron regulation in the airways is altered in asthma. a, b) Non-haem iron (NHI) levels were measured in bronchoalveolar lavage (BAL) supernatant collected from patients with severe or mild-moderate asthma and healthy controls ( $\mathrm{n}=10$ per group). c) NHI levels were correlated with $\%$ predicted forced expiratory volume in $1 \mathrm{~s}\left(\mathrm{FEV}_{1}\right)$ and d) $\mathrm{FEV}_{1}$ /forced vital capacity (FVC). e) NHI levels were also negatively correlated with inhaled corticosteroid (ICS) use. f-h) BAL cells were visualised using Perls' staining enhanced with 3,3'-diaminobenzidine tetrahydrochloride and iron-positive cells were enumerated ( $n=8-10)$. Correlation between i) iron-positive cells and \% predicted FEV 1 and $j$ ) FEV 1 /FVC was determined and are represented as Spearman's rank correlation coefficient (Spearman's rho (r)). Data are presented as mean \pm SEM, unless otherwise stated. Scale bars $=50 \mu \mathrm{m} .{ }^{*}$ : $p<0.05$ compared to respective controls; ${ }^{* *}$ : $p<0.01$ compared to respective controls.

\section{Diet-induced iron accumulation also increases key features of asthma}

To confirm our findings with $H f e^{-/-}$mice we next assessed the effects of HID-induced iron overload on disease features. Similar to our findings in $\mathrm{Hfe}^{-/-}$mice, WT mice fed a HID, which overload iron systemically (figure 6a), have increased pulmonary iron levels compared to mice fed CC (figure 6b). Furthermore, as with findings in $\mathrm{Hfe}^{-/-}$mice, diet-induced iron overload increases lung iron levels following HDM treatment, with similar levels observed in HDM-treated mice on both a HID and a CC diet (figure 6b). Consistent with findings in $\mathrm{Hfe}^{-/-}$mice, iron accumulation in the lungs of mice fed a HID is associated with airway fibrosis and AHR in the absence of HDM treatment (figure 6h-6k). HID-induced overload increases the severity of HDM-induced experimental asthma, with small airway fibrosis and AHR increased in HDM-treated mice fed a HID compared to those fed a CC diet (figures 6h-6k). There were some discrepancies observed between the effects on $\mathrm{Hfe}^{-/}$mice compared to HID fed mice. HID-fed mice did not exhibit increases in BAL leukocyte numbers, but did have elevated tissue eosinophil numbers in HDM-induced experimental asthma (figures $6 \mathrm{c}-6 \mathrm{e}$ ). These data confirm that increased iron accumulation in the lung can drive the pathogenesis and increase the severity of key asthma features. 

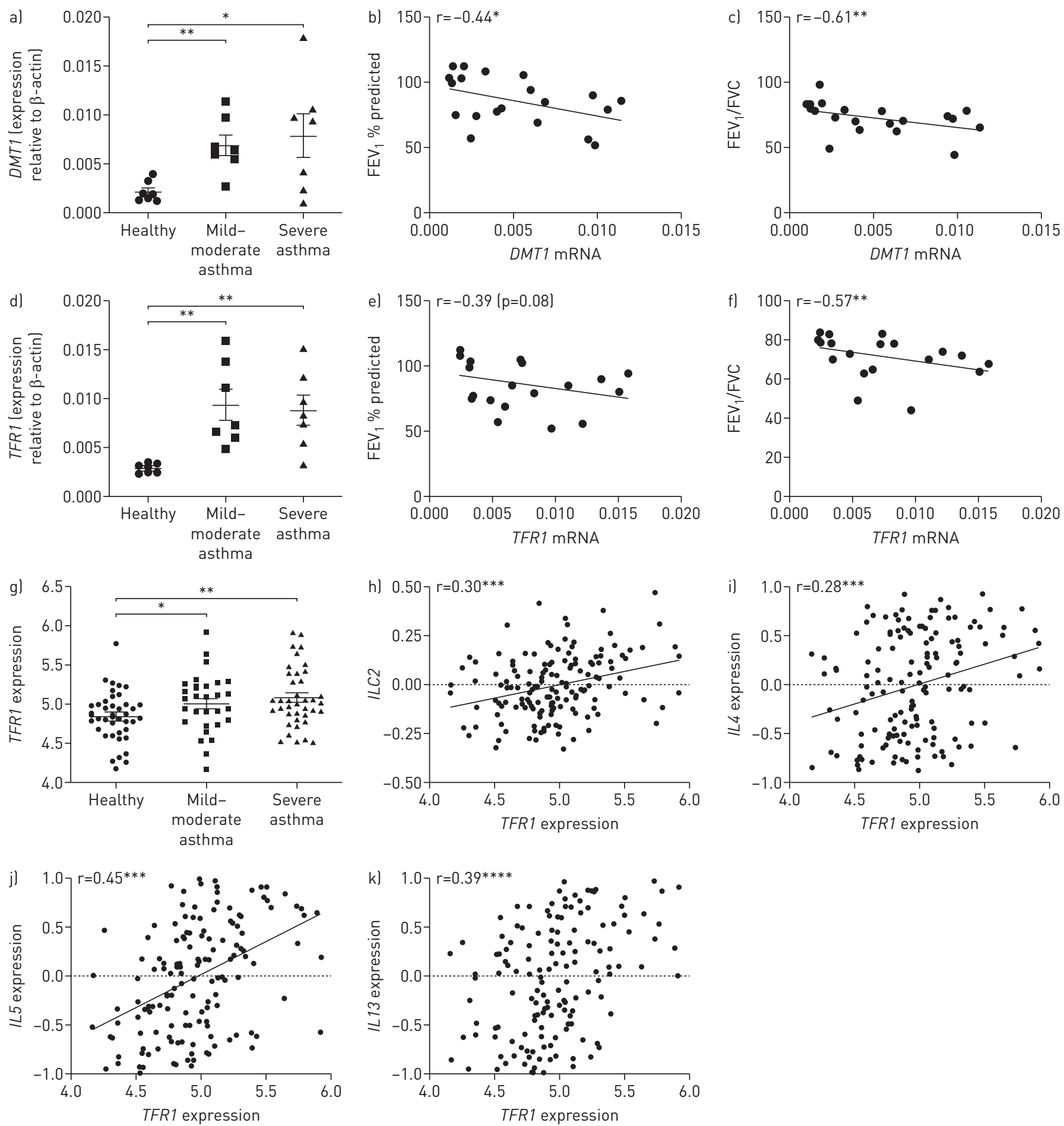

FIGURE 2 Increased divalent metal transporter 1 (DMT1) and transferrin receptor 1 (TFR1) expression in the airways correlates with impaired lung function in asthma patients. a, d) DMT1 and TFR1 mRNA expression was quantified in the airway tissues collected from seven severe asthmatic patients, seven mild-moderate asthmatic patients and six healthy controls using quantitative PCR (relative to the reference gene $\beta$-actin). $\mathrm{b}$, e) DMT1 and TFR1 expression levels negatively correlate with \% predicted forced expiratory volume in $1 \mathrm{~s}\left(\mathrm{FEV}_{1}\right)$ and $\left.\mathrm{c}, \mathrm{f}\right) \mathrm{FEV} / \mathrm{f}_{1} / \mathrm{frced}$ vital capacity (FVC). Correlations for each comparison are represented as Spearman's rank correlation coefficient (Spearman's rho (r)). TFR1 mRNA expression in the bronchial brushings of asthma patients from within the Unbiased BIOmarkers in PREDiction of respiratory disease outcomes (U-BIOPRED) cohort are shown in (g). TFR1 expression was positively correlated with h) Group 2 innate lymphoid cell (ILC2) gene signature, i) interleukin 4 (IL4), j) IL5 and K) IL 13 expression. Data are presented as mean \pm SEM, unless otherwise stated. *: p<0.05 compared to respective controls; ${ }^{* *}$ : $p<0.01$ compared to respective controls. 

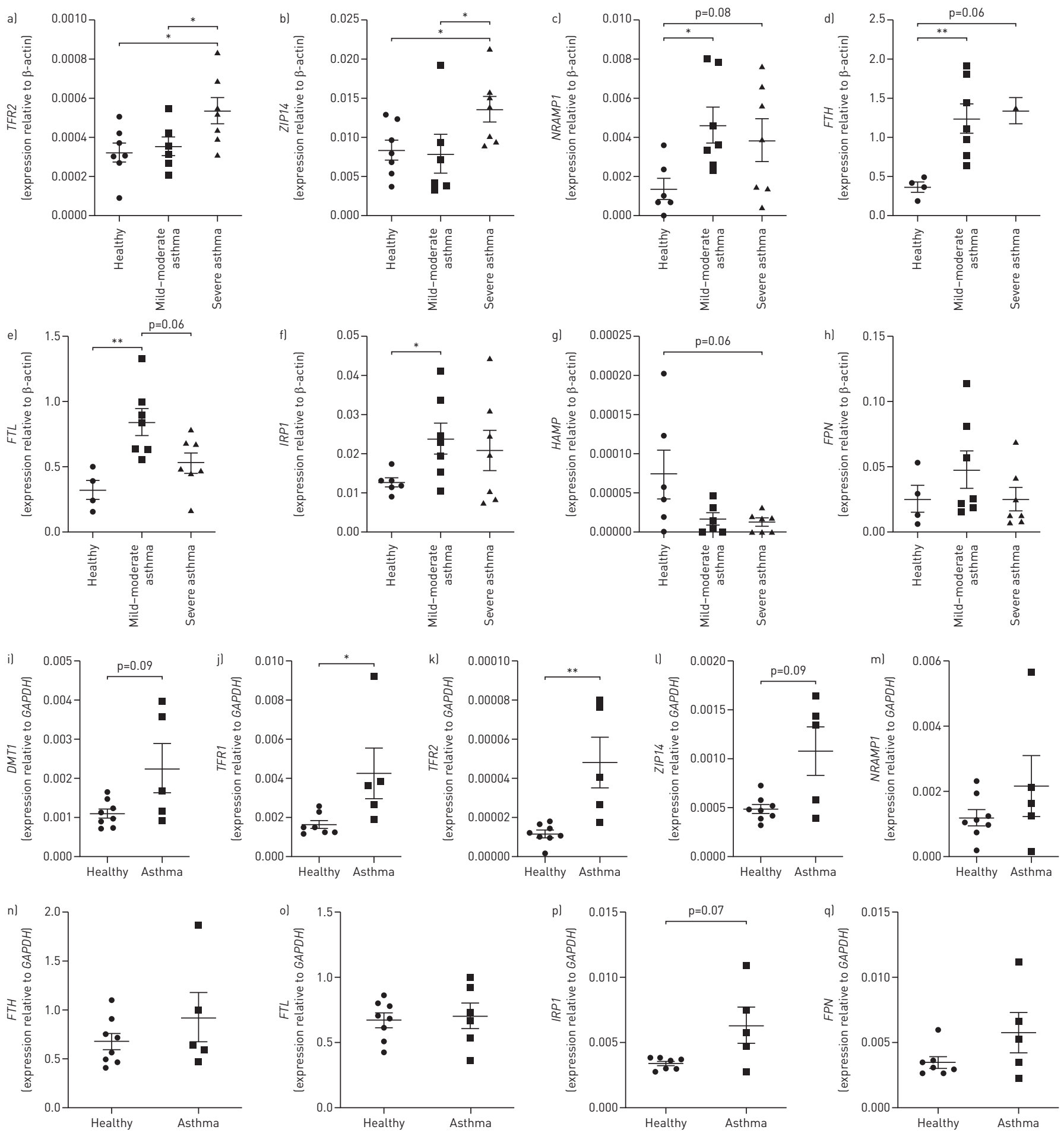

FIGURE 3 Altered expressions of iron regulatory factors in the airways of asthma patients. The mRNA expression of al transferrin receptor 2 (TFR2), b) zinc transporter (ZIP14), c) natural resistance-associated macrophage protein 1 (NRAMP1), d) ferritin heavy chain (FTH), e) ferritin light chain (FTL), f) iron regulatory protein 1 (IRP1), g) hepcidin (HAMP) and h) iron exporter ferroportin (FPN) was assessed in the airway tissues collected from seven severe asthma patients, seven mild-moderate asthma patients and six healthy controls using quantitative PCR. The mRNA expression of i) divalent metal transporter 1 (DMT1), j) transferrin receptor 1 (TFR1), k) TFR2, () ZIP14, m) NRAMP1, n) FTH, o) FTL, p) IRP1 and q) FPN was also assessed using quantitative PCR in primary bronchial epithelial cells obtained from seven severe asthma patients and eight healthy controls that had been cultured at the air-liquid interface (ALI). Expression was relative to the reference gene $\beta$-actin and glyceraldehyde 3-phosphate dehydrogenase (GAPDH) for each group, respectively. Data are presented as mean \pm SEM. ${ }^{*}$ : $p<0.05$ compared to the respective controls; ${ }^{* *}$ : $p<0.01$ compared to the respective controls. 

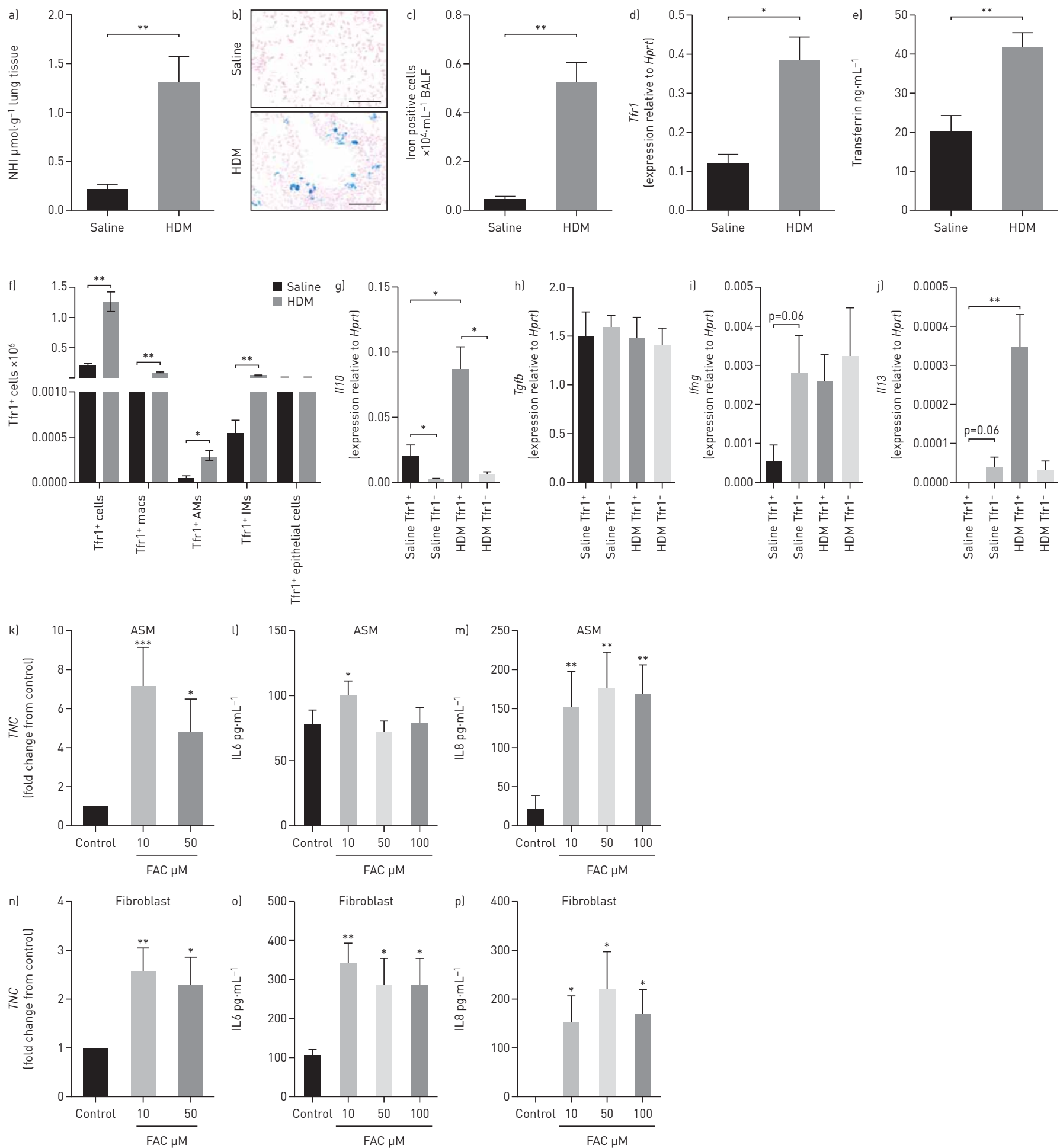

FIGURE 4 Iron levels are increased in the lung in house dust mite (HDM)-induced experimental asthma. a) Wild-type (WT) BALB/c mice at 6-8 weeks old

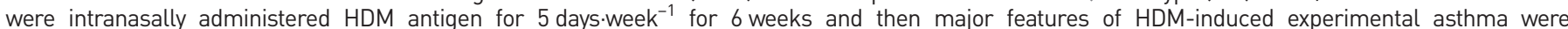
assessed. Non-haem iron (NHI) content was measured in the lung homogenates. b) Localisation of iron in the lung was assessed in lung sections using Perls' staining with 3,3'-diaminobenzidine tetrahydrochloride (DAB). c) Iron-positive cells were enumerated in bronchoalveolar lavage (BAL) cells using Perls' staining. d) Tfr1 expression was measured in airway tissues using quantitative PCR. e) Transferrin levels were measured by enzyme-linked immunosorbent assay (ELISA). f) Tfr $1^{+}$cells were sorted using fluorescence-activated cell sorting (FACS) analysis. Expression of g) interleukin 10 (//10), h) transforming growth factor beta (Tgfb), i) interferon gamma (lfng) and j) $/ 113$ was assessed in sorted Tfr $1^{+}$and Tfr $1^{-}$macrophages in the presence and absence of HDM-induced experimental asthma using quantitative PCR. $\mathrm{k}-\mathrm{m}$ ) Levels of tenascin C (TNC) and interleukin 6 (IL6) and IL8 were measured in ferric ammonium citrate (FAC)-treated airway smooth muscle (ASM) cells and $n-p)$ lung fibroblast cells using quantitative PCR and ELISA, respectively. Data are presented as mean \pm SEM $(n=6-8)$, pooled from two repeat experiments. Scale bars $=50 \mu \mathrm{m}$. BALF: bronchoalveolar lavage fluid; mac: macrophage; AM: alveolar macrophage; IM: interstitial macrophage; Hprt: hypoxanthine phosphoribosyltransferase. *: p<0.01 compared to PBS controls; $^{* *}$ : $p<0.001$ compared to PBS controls; ${ }^{* * *}: p<0.0001$ compared to PBS controls. 
Interestingly, mice fed a LID, which had reduced liver iron levels (figure 6a), did not have reduced lung iron levels in the absence of HDM treatment (figure 6b). However, mice fed a LID did have reduced lung iron accumulation in HDM-induced experimental asthma (figure 6b), which is associated with decreases in total leukocyte numbers in BAL and mucus secreting cell (MSC) numbers around the airways (figures $6 c$, $6 \mathrm{f}$ and $6 \mathrm{~g}$ ). The decrease in lung iron levels has no effect on HDM-induced airway fibrosis or AHR (figures 6h-6k).

Together, these data show that the relationship between lung iron levels and the pathogenesis and severity of asthma is complex. Nevertheless, these data provide new evidence that increased iron accumulation in the lung plays key roles in driving the characteristic features of asthma.

\section{Discussion}

Clinically, both low $[7,8]$ and high $[10,11,36]$ systemic iron has been reported in asthma. In most clinical studies, iron levels are assessed systemically in serum/plasma but not locally in the lung. Indeed, only one study has been reported showing that low iron in exhaled breath condensate is associated with asthma [9]. However, it is unclear whether altered iron levels play a role in pathogenesis of disease, or if they are a consequence of it. To investigate the potential role of iron level and/or regulation in the lung in the pathogenesis and severity of asthma, we first assessed iron levels in the BAL supernatant and cells of patients with mild-moderate asthma and severe asthma compared to healthy controls. We show, for the first time, that NHI levels in BAL supernatant are markedly lower in asthma patients compared with healthy controls. Significantly, when the asthma patients are separated into mild-moderate and severe groups, NHI levels are significantly further reduced in patients with severe asthma. In contrast to the decreased iron levels in BAL supernatant, we show that the number of iron-loaded cells are increased in the BAL of patients with mild-moderate asthma and severe asthma. Both the levels of extracellular iron in supernatant and iron-loaded cell numbers in BAL correlate with lung function, with higher extracellular iron levels associated with better lung function and higher iron-positive cells associated with worse lung function. This is the first report showing correlations between airway iron homeostasis and key lung-function parameters. Taken together, our data suggest that lower extracellular iron in the airways and higher intracellular iron in the airways are associated with asthma and are linked with disease severity.

Our clinical data, which suggests that asthma is associated with increased iron sequestration/accumulation into cells and/or tissues, is supported by our findings that DMT1 and/or TFR1 expression is significantly increased in the airways in clinical and experimental asthma and correlates with impairment of lung function. In the lung, iron is mostly imported into cells by TFR1, as well as by DMT1 and NRAMP1 [1, 37-39]. Thus, increased expression of DMT1 and TFR1 may contribute to the decreased extracellular iron and increased intracellular iron that we observe in BAL of asthma patients. These changes may be a consequence of chronic inflammatory responses that underpin disease. Inflammation is a well-known promoter of iron sequestration into cells, predominantly due to cytokine-mediated modification of hepcidin responses [40]. A previous study showed that liver specific $\mathrm{Hepc}^{-/-}$mice had increased iron in the lung similar to Hepc globally deficient mice, suggesting that systemic hepcidin plays a predominant role in regulating iron levels in the lung [41]. However, studies are still required to determine whether hepcidin regulation occurs at a subtle level locally within the lung. IL6 also enhances TFR1 responses and iron uptake in hepatocytes [42]. TFR expression is upregulated in the lungs of rats exposed to lipopolysaccharide [43]. We extend these findings by showing that TFR1 expression is associated with increased T2 inflammatory gene (IL4, IL5 and IL13) expression in the asthmatic airways. We also show that $\mathrm{Tfr}^{+}$macrophages are increased in the lungs during HDM-induced experimental asthma and that these cells display a phenotype of increased Il13 expression. We also show that exogenous iron increases pro-inflammatory cytokine and ECM responses in human ASM cells and/or lung fibroblasts. Together these data suggest that increased extracellular iron levels in lung tissue may drive disease through increasing pathological responses in ASM cells and fibroblasts. Our data suggest that increased iron sequestration by $\mathrm{Tfr}^{+}$macrophages, perhaps as a protective response to increased extracellular iron levels and/or innate pro-inflammatory responses in the asthmatic airway, may result in the induction of T2 inflammatory responses that play a key role in the pathogenesis of asthma.

Whilst our initial findings suggest strong links between the sequestration/accumulation of iron into cells/ tissues and the pathogenesis and severity of asthma, they do not show whether changes in iron homeostasis that result in increased iron accumulation in cells is a driver or consequence of disease. To investigate the roles of pulmonary iron accumulation in disease, we employed a complementary suite of murine models of iron overload and chronic HDM-induced experimental asthma. We show that both genetic ( $\mathrm{Hfe}^{-/-}$mice) and dietary (HID fed mice) models of iron overload result in significant accumulation of iron in lung tissues. This iron accumulation is similar to that observed in HDM-induced experimental asthma. Furthermore, iron overload induced pulmonary iron accumulation results in the 

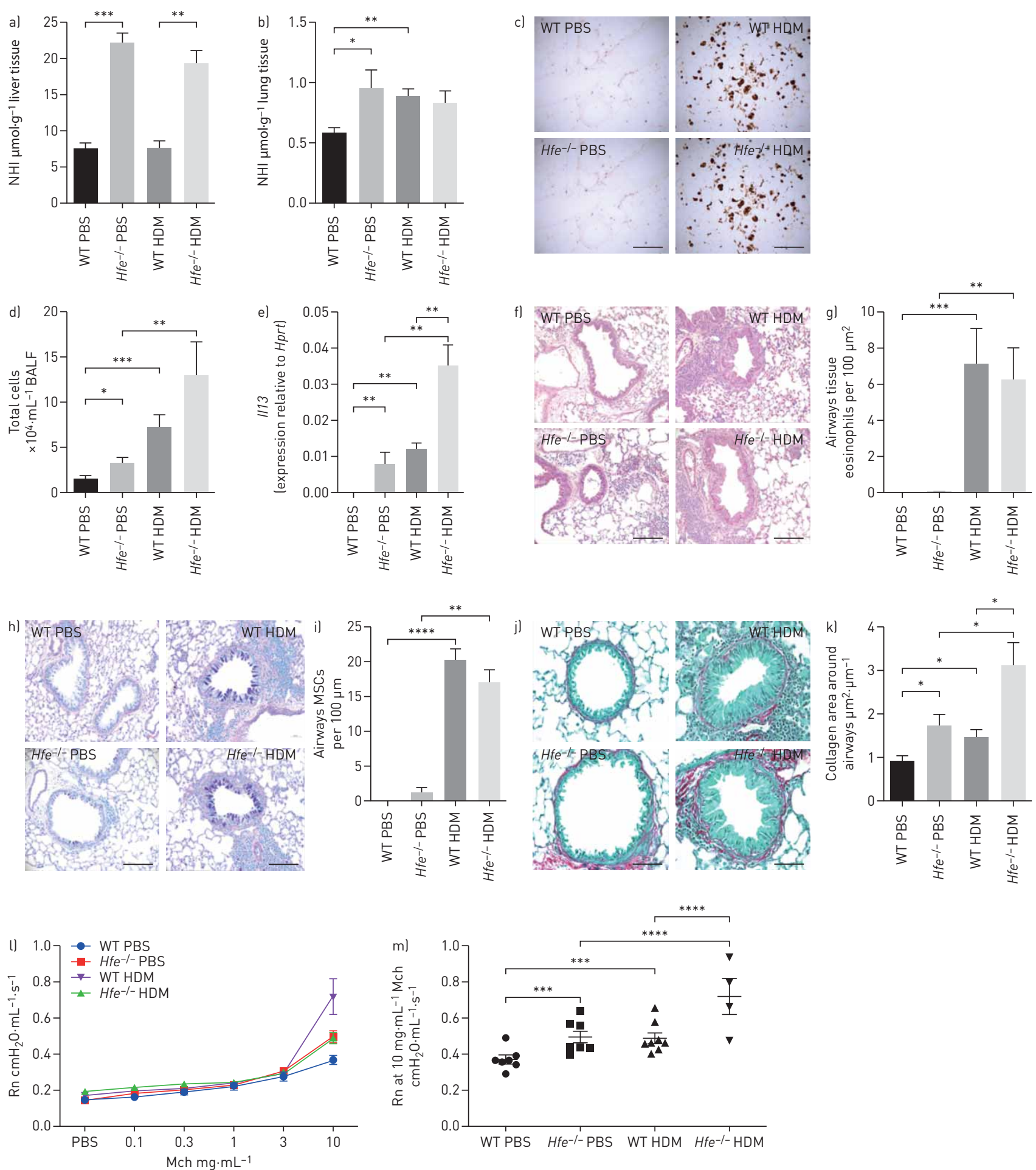

FIGURE 5 Absence of the haemochromatosis protein gene (Hfe) increases the severity of house dust mite (HDM)-induced experimental asthma. HDMs were administered to wild-type (WT) AKR and $\mathrm{Hfe}^{-/-}$mice at $\sim 36$ weeks old for 5 days.week ${ }^{-1}$ for 6 weeks and then the hallmark features of experimental asthma were assessed. Levels of non-haem iron (NHI) were measured in the a) liver and b) lung. c) Localisation of iron in the lung was assessed in lung sections using Perls' staining with 3,3'-diaminobenzidine tetrahydrochloride (DAB). d) Total leukocytes were enumerated in processed bronchoalveolar lavage (BAL). e) Interleukin 13 (//13) mRNA expression was measured by quantitative PCR. f, g) Tissue eosinophilic inflammation was quantified in chrome salt fixation-stained lung sections. $h$, i) Mucus secreting cells (MSCs) were enumerated around the airways in periodic acid-Schiff (PAS)-stained lung sections. j, k) Area of collagen deposition surrounding the basement membrane of small airways was determined in Sirius Red stained lung tissue sections, in six to eight airways per mouse, using ImageJ (version 1.47, NIH, Bethesda, MD, USA). () Airway hyper-responsiveness (AHR), in terms of central airway resistance (Rn), was measured in response to increasing concentrations of nebulised methacholine (Mch). m) Rn at $10 \mathrm{mg} \cdot \mathrm{mL}^{-1} \mathrm{Mch}$ was determined from AHR curves. Data are presented as mean \pm SEM $(n=6-10)$, pooled from two repeat experiments. Scale bars $=50 \mu \mathrm{m}$. BALF: bronchoalveolar lavage fluid. ${ }^{*}: p<0.05 ;{ }^{* *}: p<0.01 ;{ }^{* * *} p<0.001$; $* * * *: p<0.0001$. 

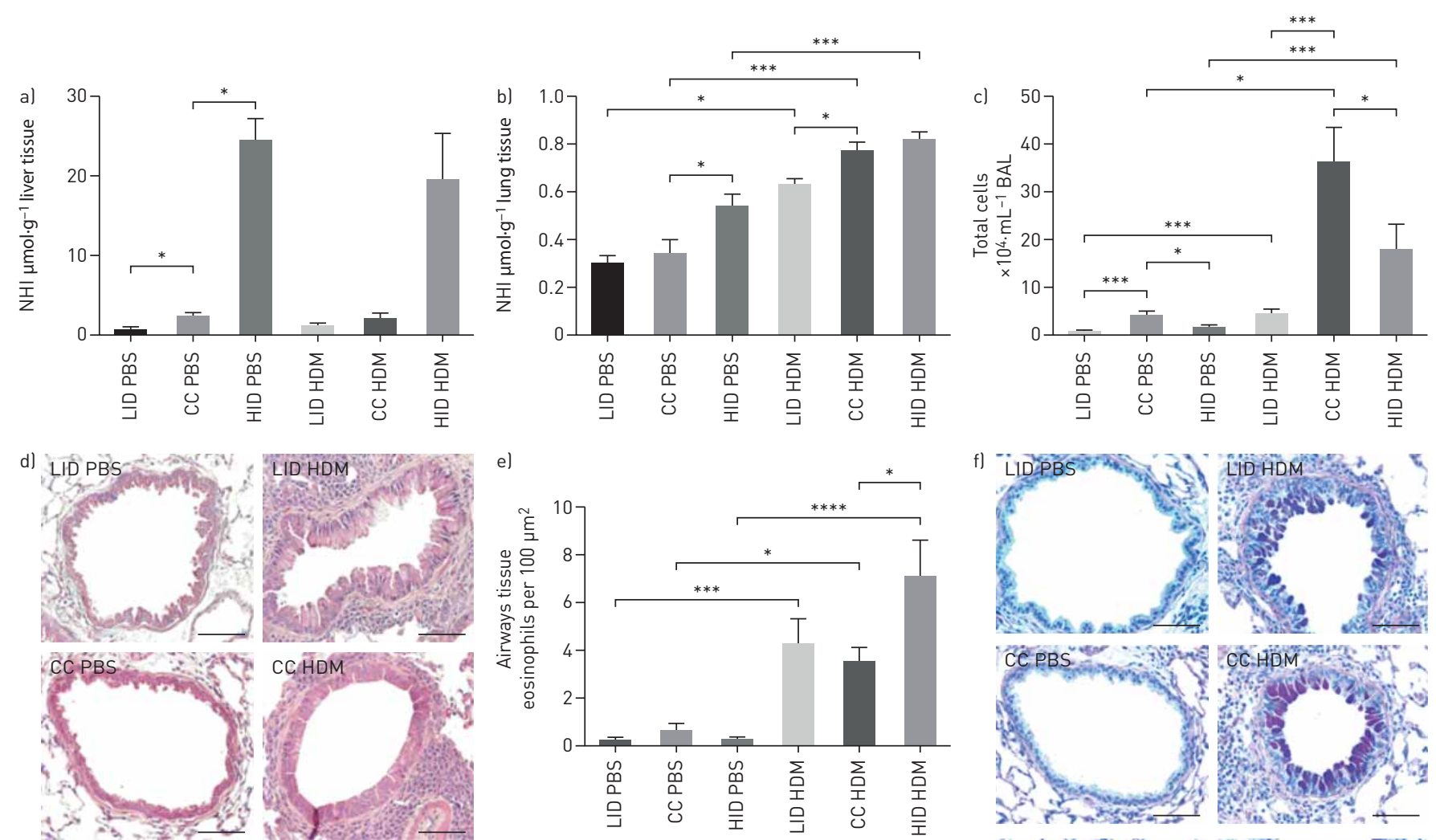

HID PBS HID HDM
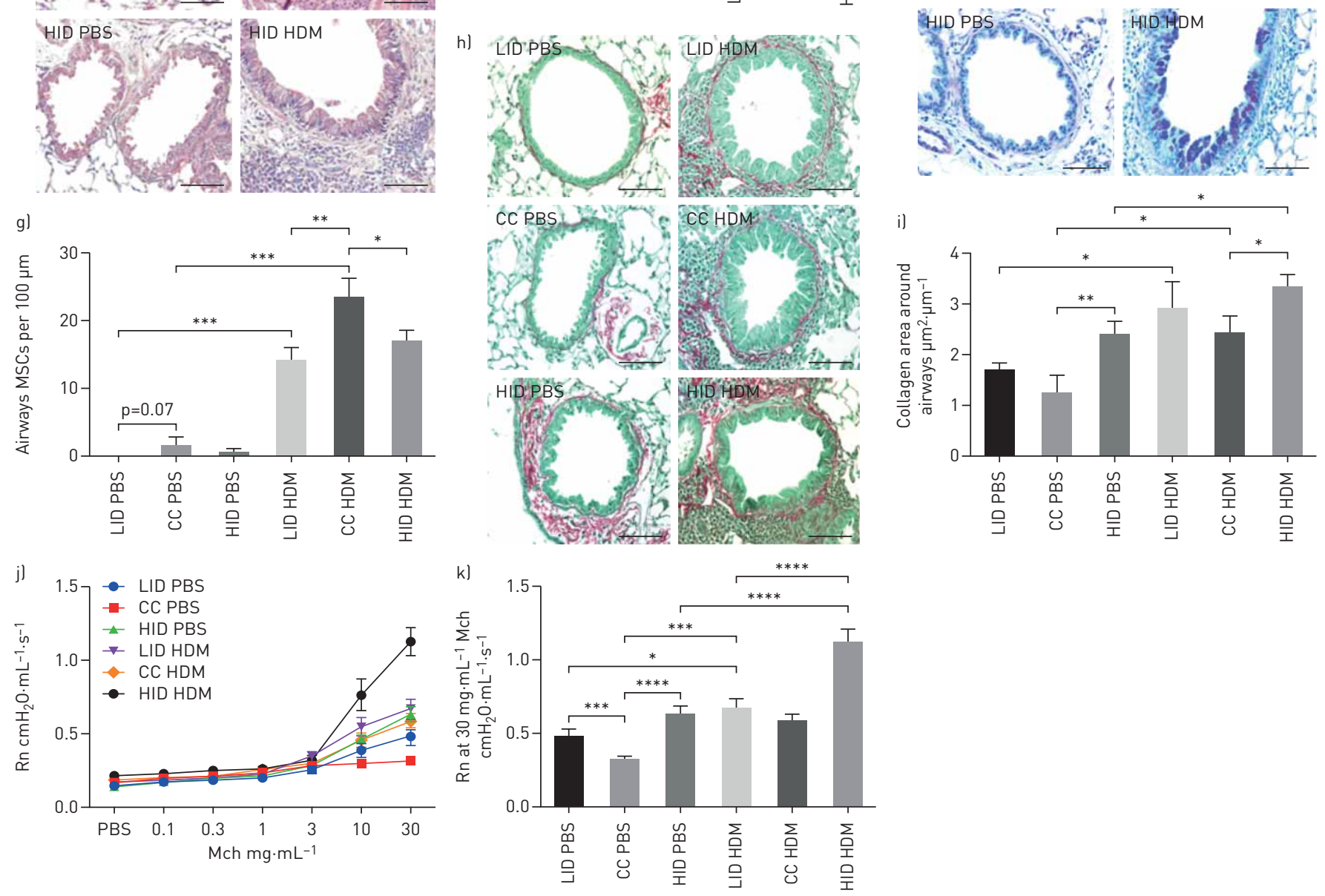
FIGURE 6 High iron diet induced iron accumulation increases the key features of asthma. Wild-type (WT) BALB/c female mice at 6-8 weeks old were fed a low iron diet (LID), normal control chow (CC) or a high iron diet (HID) and were intranasally administered with house dust mite (HDM) antigen or phosphate-buffered saline (PBS) 5 days week $^{-1}$ for up to 6 weeks. Non-haem iron (NHI) content was measured in the a) liver and b) lung by NHI assay. c) Total leukocytes were enumerated in processed bronchoalveolar lavage (BAL). d, e) Numbers of eosinophils were quantified around the most inflamed airways in chrome salt fixation-stained lung sections. f, g) Mucus secreting cells (MSCs) were enumerated around airways in periodic acid-Schiff (PAS)-stained lung sections. h, i) Area of collagen deposition surrounding the basement membrane of small airways was quantified in Sirius Red stained lung tissue sections, in six to eight airways per mouse, using ImageJ (version 1.47, NIH, Bethesda, MD, USA). j) Airway hyper-responsiveness (AHR) was measured, in terms of central airway resistance (Rn), in response to inhaled increasing concentrations of methacholine (Mch). $\mathrm{k}$ ) Rn at $30 \mathrm{mg} \cdot \mathrm{mL}^{-1} \mathrm{Mch}$ was determined from AHR curves. Data are presented as mean \pm SEM ( $\mathrm{n}=6-19$ ), pooled from three repeat experiments. Scale bars $=50 \mu \mathrm{m} .{ }^{*}: p<0.05$ compared to the respective controls; ${ }^{* *}$ : $p<0.01$ compared to the respective controls; $^{* * *}$ : $p<0.001$ compared to the respective controls; ${ }^{* * *}: p<0.0001$ compared to the respective controls.

presentation of many of the key features of asthma, including airway inflammation, T2 cytokine (IL13) production, airway fibrosis and AHR. Together, these data provide strong evidence that increased iron levels in tissue play a key functional role in the pathogenesis and increased severity of asthma.

To conclude, complementary clinical and experimental studies show a strong relationship between iron level and regulation, and the pathogenesis and severity of asthma. We show, for the first time, that altered levels of iron and iron-related gene expression in the airways of patients with asthma are linked with lung function, with evidence for increased iron accumulation into tissues being detrimental for disease. Using murine models, we show that increased lung iron accumulation drives the pathogenesis and severity of key features of asthma. Due to the small amounts of tissue available (or lack of available RNA) we were not able to measure iron levels in airway tissue biopsies, or iron regulatory gene expression in BAL cells. We also used bronchoscopy samples from two different cohorts. These are limitations of the current study. Nevertheless, our findings highlight the need for further studies to investigate the mechanisms that underpin the effects of iron dysregulation on the pathogenesis and severity of asthma, as well as to explore and test novel iron-targeted therapies. Given the interactions that occur between microbes and iron, and the role of infection in asthma, further studies are also required to explore the inter-relationship between microbiomes, iron levels/regulation, mucosal immunity and asthma.

Conflict of interest: M.K. Ali has nothing to disclose. R.Y. Kim has nothing to disclose. A.C. Brown has nothing to disclose. J.R. Mayall has nothing to disclose. R. Karim has nothing to disclose. J.W. Pinkerton has nothing to disclose. G. Liu has nothing to disclose. K.L. Martin has nothing to disclose. M.R. Starkey has nothing to disclose. A.L. Pillar has nothing to disclose. C. Donovan has nothing to disclose. P.S. Pathinayake has nothing to disclose. O.R. Carroll has nothing to disclose. D. Trinder has nothing to disclose. H.L. Tay has nothing to disclose. Y.E. Badi has nothing to disclose. N.Z. Kermani has nothing to disclose. Y-K. Guo has nothing to disclose. R. Aryal has nothing to disclose. S. Mumby has nothing to disclose. S. Pavlidis has nothing to disclose. I.M. Adcock reports grants from EU-IMI, during the conduct of the study. J. Weaver has nothing to disclose. D. Xenaki has nothing to disclose. B.G. Oliver has nothing to disclose. E.G. Holliday has nothing to disclose. P.S. Foster has nothing to disclose. P.A. Wark has nothing to disclose. D.M. Johnstone has nothing to disclose. E.A. Milward has nothing to disclose. P.M. Hansbro has nothing to disclose. J.C. Horvat has nothing to disclose.

Support statement: J.C. Horvat is supported by grants and fellowships from Cystic Fibrosis Australia and the Australian Cystic Fibrosis Research Trust and the University of Newcastle, Australia. P.M. Hansbro and D. Trinder are funded by fellowships from the NHMRC (1079187 and 1020437). P.M. Hansbro is also funded by an investigator grant from the NHMRC of Australia (1175134). Funding information for this article has been deposited with the Crossref Funder Registry.

\section{References}

1 Ali MK, Kim RY, Karim R, et al. Role of iron in the pathogenesis of respiratory disease. Int J Biochem Cell Biol 2017; 88: 181-195.

2 Kemna E, Pickkers P, Nemeth E, et al. Time-course analysis of hepcidin, serum iron, and plasma cytokine levels in humans injected with LPS. Blood 2005; 106: 1864-1866.

3 Cherayil BJ. Pathophysiology of iron homeostasis during inflammatory states. J Pediatr 2015; 167: S15-S19.

4 Nwaru BI, Hayes H, Gambling L, et al. An exploratory study of the associations between maternal iron status in pregnancy and childhood wheeze and atopy. Br J Nutr 2014; 112: 2018-2027.

5 Weigert R, Dosch NC, Bacsik-Campbell ME, et al. Maternal pregnancy weight gain and cord blood iron status are associated with eosinophilia in infancy. J Perinatol 2015; 35: 621-626.

6 Shaheen SO, Newson RB, Henderson AJ, et al. Umbilical cord trace elements and minerals and risk of early childhood wheezing and eczema. Eur Respir J 2004; 24: 292-297.

$7 \quad$ Ramakrishnan K, Borade A. Anemia as a risk factor for childhood asthma. Lung India 2010; 27: 51-53.

8 Brigham EP, McCormack MC, Takemoto CM, et al. Iron status is associated with asthma and lung function in US women. PLoS One 2015; 10: e0117545.

9 Vlasic Z, Dodig S, Cepelak I, et al. Iron and ferritin concentrations in exhaled breath condensate of children with asthma. J Asthma 2009; 46: 81-85.

10 Kocyigit A, Armutcu F, Gurel A, et al. Alterations in plasma essential trace elements selenium, manganese, zinc, copper, and iron concentrations and the possible role of these elements on oxidative status in patients with childhood asthma. Biol Trace Elem Res 2004; 97: 31-41.

11 Narula MK, Ahuja GK, Whig J, et al. Status of lipid peroxidation and plasma iron level in bronchial asthmatic patients. Indian J Physiol Pharmacol 2007; 51: 289-292. 
12 Bibi H, Vinokur V, Waisman D, et al. Zn/Ga-DFO iron-chelating complex attenuates the inflammatory process in a mouse model of asthma. Redox Biol 2014; 2: 814-819.

13 Maazi H, Shirinbak S, Bloksma N, et al. Iron administration reduces airway hyperreactivity and eosinophilia in a mouse model of allergic asthma. Clin Exp Immunol 2011; 166: 80-86.

14 Kuo CS, Pavlidis S, Loza M, et al. A transcriptome-driven analysis of epithelial brushings and bronchial biopsies to define asthma phenotypes in U-BIOPRED. Am J Respir Crit Care Med 2017; 195: 443-455.

15 Zhou XY, Tomatsu S, Fleming RE, et al. HFE gene knockout produces mouse model of hereditary hemochromatosis. Proc Natl Acad Sci USA 1998; 95: 2492-2497.

16 Gold MJ, Hiebert PR, Park HY, et al. Mucosal production of uric acid by airway epithelial cells contributes to particulate matter-induced allergic sensitization. Mucosal Immunol 2016; 9: 809-820.

17 Kaldor I. Studies on intermediary iron metabolism. V. The measurement of non-haemoglobin tissue iron. Aust Exp Biol Med Sci 1954; 32: 795-799.

18 Collison A, Hatchwell $\mathrm{L}$, Verrills $\mathrm{N}$, et al. The E3 ubiquitin ligase midline 1 promotes allergen and rhinovirus-induced asthma by inhibiting protein phosphatase 2A activity. Nat Med 2013; 19: 232-237.

19 Horvat JC, Starkey MR, Kim RY, et al. Early-life chlamydial lung infection enhances allergic airways disease through age-dependent differences in immunopathology. J Allergy Clin Immunol 2010; 125: 617-625.

20 Asquith KL, Horvat JC, Kaiko GE, et al. Interleukin-13 promotes susceptibility to chlamydial infection of the respiratory and genital tracts. PLoS Pathog 2011; 7: e1001339.

21 Beckett EL, Stevens RL, Jarnicki AG, et al. A new short-term mouse model of chronic obstructive pulmonary disease identifies a role for mast cell tryptase in pathogenesis. J Allergy Clin Immunol 2013; 131: 752-762.

22 Liu G, Cooley MA, Jarnicki AG, et al. Fibulin-1 regulates the pathogenesis of tissue remodeling in respiratory diseases. JCI Insight 2016; 1: e86380.

23 Horvat JC, Starkey MR, Kim RY, et al. Chlamydial respiratory infection during allergen sensitization drives neutrophilic allergic airways disease. J Immunol 2010; 184: 4159-4169.

24 Kim RY, Horvat JC, Pinkerton JW, et al. MicroRNA-21 drives severe, steroid-insensitive experimental asthma by amplifying phosphoinositide 3-kinase-mediated suppression of histone deacetylase 2. J Allergy Clin Immunol 2017; 139: 519-532.

25 Nair PM, Starkey MR, Haw TJ, et al. Targeting PP2A and proteasome activity ameliorates features of allergic airway disease in mice. Allergy 2017; 72: 1891-1903.

26 Liu G, Cooley MA, Nair PM, et al. Airway remodelling and inflammation in asthma are dependent on the extracellular matrix protein fibulin-1c. J Pathol 2017; 243: 510-523.

27 Essilfie AT, Horvat JC, Kim RY, et al. Macrolide therapy suppresses key features of experimental steroid-sensitive and steroid-insensitive asthma. Thorax 2015; 70: 458-467.

28 Thorburn AN, Foster PS, Gibson PG, et al. Components of Streptococcus pneumoniae suppress allergic airways disease and NKT cells by inducing regulatory T cells. J Immunol 2012; 188: 4611-4620.

29 Hansbro PM, Hamilton MJ, Fricker M, et al. Importance of mast cell Prss31/transmembrane tryptase/tryptase- $\gamma$ in lung function and experimental chronic obstructive pulmonary disease and colitis. I Biol Chem 2014; 289: 18214-18227.

30 Kaiko GE, Phipps S, Hickey DK, et al. Chlamydia muridarum infection subverts dendritic cell function to promote Th2 immunity and airways hyperreactivity. J Immunol 2008; 180: 2225-2232.

31 Thorburn AN, O'Sullivan BJ, Thomas R, et al. Pneumococcal conjugate vaccine-induced regulatory $\mathrm{T}$ cells suppress the development of allergic airways disease. Thorax 2010; 65: 1053-1060.

32 Krimmer D, Ichimaru Y, Burgess J, et al. Exposure to biomass smoke extract enhances fibronectin release from fibroblasts. PLoS One 2013; 8: e83938.

33 Hsu AC, Starkey MR, Hanish I, et al. Targeting PI3K-p110 $\alpha$ suppresses influenza virus infection in chronic obstructive pulmonary disease. Am J Respir Crit Care Med 2015; 191: 1012-1023.

34 Starkey MR, Nguyen DH, Brown AC, et al. Programmed death ligand 1 promotes early-life chlamydia respiratory infection-induced severe allergic airway disease. Am J Respir Cell Mol Biol 2016; 54: 493-503.

35 Bjorklund AK, Forkel M, Picelli S, et al. The heterogeneity of human CD127(+) innate lymphoid cells revealed by single-cell RNA sequencing. Nat Immunol 2016; 17: 451-460.

36 Ekmekci OB, Donma O, Sardogan E, et al. Iron, nitric oxide, and myeloperoxidase in asthmatic patients. Biochemistry Mosc 2004; 69: 462-467.

37 Cloonan SM, Mumby S, Adcock IM, et al. The IRONy of iron-overload and iron-deficiency in chronic obstructive pulmonary disease. Am J Respir Crit Care Med 2017; 196: 1103-1112.

38 Kim J, Molina RM, Donaghey TC, et al. Influence of DMT1 and iron status on inflammatory responses in the lung. Am J Physiol Lung Cell Mol Physiol 2011; 300: L659-L665.

39 Ghio AJ, Carter JD, Richards JH, et al. Iron and iron-related proteins in the lower respiratory tract of patients with acute respiratory distress syndrome. Crit Care Med 2003; 31: 395-400.

40 Ganz T, Nemeth E. Iron homeostasis in host defence and inflammation. Nat Rev Immunol 2015; 15: 500-510.

41 Deschemin JC, Mathieu JRR, Zumerle S, et al. Pulmonary iron homeostasis in hepcidin knockout mice. Front Physiol 2017; 8: 804

42 Ahmad S, Sultan S, Naz N, et al. Regulation of iron uptake in primary culture rat hepatocytes: the role of acute-phase cytokines. Shock 2014; 41: 337-345.

43 Upton RL, Chen Y, Mumby S, et al. Variable tissue expression of transferrin receptors: relevance to acute respiratory distress syndrome. Eur Respir J 2003; 22: 335-341. 